\title{
Effects of Fusarium graminearum and Fusarium poae on disease parameters, grain quality and mycotoxin contamination in barley (Part II)
}

M. Martínez ${ }^{1}$, D. Ramírez Albuquerque ${ }^{2}$, M.I. Dinolfo ${ }^{1}$, F. Biganzoli ${ }^{3}$, V. Fernández Pinto², S. A. Stenglein ${ }^{1 *}$

${ }^{1}$ Laboratorio de Biología Funcional y Biotecnología (BIOLAB)-INBIOTEC-CONICETUNCPBA-CICBA, Facultad de Agronomía, Av. República de Italia \# 780. 7300 Azul, Buenos Aires, Argentina.

2Departamento de Química Orgánica. Facultad de Ciencias Exactas y Naturales, UBA. Buenos Aires, Argentina.

${ }^{3}$ Departamento de Métodos Cuantitativos y Sistemas de Información. Facultad de Agronomía, UBA. Buenos Aires, Argentina.

*E-mail: stenglein@faa.unicen.edu.ar

Running title: Barley/F.graminearum/F. poae interaction

This article has been accepted for publication and undergone full peer review but has not been through the copyediting, typesetting, pagination and proofreading process which may lead to differences between this version and the Version of Record. Please cite this article as doi: 10.1002/jsfa.10354 


\begin{abstract}
BACKGROUND: Barley is one of the most important winter crops in the world, with multiple uses such as human consumption, animal feed and for the malting industry. This crop is affected by different diseases, such as Fusarium Head Blight (FHB), that causes losses in yield and quality. In the last years F. graminearum and F. poae were two of the most frequently isolated species in barley grains, so the aim of this study was to evaluate the interaction between these Fusarium species and the effects on disease parameters, grain quality and mycotoxin contamination on five barley genotypes under field conditions.
\end{abstract}

RESULTS: Statistical differences between Fusarium treatments for some parameters depending mainly on the year/genotype were found. The results showed that germination process was affected by both Fusarium species. As to grain quality and the different hordein fractions, it was observed that F. graminearum affects preferentially D and Chordeins Different concentrations of nivalenol, deoxynivalenol and their acetylated derivatives (3-ADON and 15-ADON) were detected.

CONCLUSIONS: In the present work, no evidence of synergism between $F$. graminearum and $F$. poae were found regarding disease parameters and mycotoxin contamination. However, at least in the years with favorable climatic conditions to FHB development and depending on the barley genotype, a continuous monitoring is deemed 
necessary to prevent the negative impact on protein composition and germinative parameters Keywords: Fusarium, barley, mycotoxins, disease parameters, grain quality, plant-pathogen interaction.

\section{Introduction}

Barley (Hordeum vulgare L.) is one of the most sown crops in the world due to its multiple uses such as human consumption, animal feed and for the malting industry. Barley grains are the major raw material used for brewing, being the malting barley the major input for the brewing industry. Within the commercial quality parameters for malting barley, the most important ones are germinative power $(>95 \%)$, protein concentration $(<12 \%)$ and screening percentage ( $>85 \%$ grains with a diameter greater than 2.5 millimeters) ${ }^{1,2}$ In the last few years, the production of two-row barley has grown significantly and the main destination is the brewing industry, although the use of barley for animal feed is also increasing. The global barley production in 2017/2018 was about 142.97 million tons, with the US Department of Agriculture (USDA) estimating that the production for 2018/2019 will be about 147.57 million tons. The major barley producers are the European Union (59.09 million tons) and Russia (20.18 million tons). ${ }^{3}$

Regarding grain quality, a group of storage proteins highly abundant in cereal seeds is the prolamins, known as hordeins in barley and representing the major fraction of the endosperm storage proteins in grains. The type of protein stored influences malt extract regardless of grain protein concentration. Hordeins are classified into three groups: 1) high molecular weight (D-hordeins); 2) poor in sulfur (C-hordeins); 3) rich in 
sulfur (B-hordeins). The D-hordeins have an approximate size of $100 \mathrm{kDa}$ and represent less than $10 \%$ of the total seed content. The C-hordeins have a size of $55-70 \mathrm{kDa}$, do not contain cysteine residues, so they do not tend to form complexes with other proteins and their abundance is $10-20 \%$. B-hordeins have a size of $36-44 \mathrm{kDa}$, are rich in cysteine residues, therefore they can form intra or interchain disulfide bridges and are the most abundant (75-80\%). ${ }^{4}$ The B-hordeins represent the primary factor affecting grain protein content, with a negative correlation between the B-hordein content and malt extract. ${ }^{5}$

Fusarium Head Blight (FHB) is one of the most devastating diseases that occur in barley in most areas of the world causing not only damage to crops but also serious economic losses. FHB is observed mainly in the regions with a warm and wet climate coinciding with the flowering stage of this cereal. Currently, Fusarium graminearum is the dominant species isolated worldwide but in the last years, F. poae has been commonly found by several researchers in diverse substrates such as barley and wheat ${ }^{6}$. FHB causes quantitative and qualitative damage to crops with a significant impact on yield and several functional parameters of grain related to malting and brewing quality, with beer gushing (violent overfoaming of beer) being the most infamous. In general, pronounced effects on germination, soluble nitrogen, free amino nitrogen, wort color, and $\beta$-glucan levels were reported and many of the changes likely resulted from enzymes produced by Fusarium spp. ${ }^{1,6,7,8,9}$ However, the greatest concern for the use of barley infected with FHB has been the presence of mycotoxins. ${ }^{1,7}$

Fusarium has the capacity to produce trichothecenes, one of the most important groups of mycotoxins that can cause harmful effects on humans and animals through 
ingestion of contaminated cereal grains. Variations in environmental conditions, crops and storage factors can influence the type and amount of mycotoxins produced by different Fusarium species. ${ }^{10} \mathrm{~F}$. graminearum has the capacity to produce a wide spectrum and quantity of mycotoxins, such as deoxynivalenol (DON), that can be acutely lethal when consumed in large amounts, and its acetylated derivatives 3-ADON and 15ADON. DON has been found to carry through malting and brewing into finished beer and has been reported in commercial beers at levels of 0.30 to $569 \mu \mathrm{g} / \mathrm{L} .{ }^{1,11}$. On the other hand, F. poae has special importance since it is the main Fusarium pathogen able to produce nivalenol (NIV), an important mycotoxin that in high concentrations can inhibit cell proliferation and produces cytotoxic effects on cells. ${ }^{12}$ High NIV concentrations were found in commercial samples of beer reaching values of $2.40 \pm 1.9 \mu \mathrm{g} / \mathrm{L} .{ }^{13}$ However, the European Scientific Committee on Food (SCF) has established limits for DON only, considering a tolerable daily intake of $1 \mathrm{mg} / \mathrm{kg}$ body weight, while for NIV established a provisional limit value of $0.7 \mathrm{mg} / \mathrm{kg}$ body weight. ${ }^{14}$

It is known that the competition for resources between Fusarium species can produce more toxins under stress conditions, while in co-inoculations no evidence was found to support synergism between fungal isolates in causing visual symptoms ${ }^{15}$. The aim of this study was to evaluate the effects of the presence of F. graminearum and $F$. poae in terms of disease parameters, grain quality and mycotoxin contamination in tworow barley under field conditions.

\section{Materials and methods}


Fusarium isolates. A mixture of four isolates of F. graminearum with the ability to produce DON, 3-ADON and 15-ADON in vitro were selected for the production of the inoculum (isolates 3.4, 88.1, 92.2 and 129.1) ${ }^{16}$ while another mixture of four isolates of F. poae (FP-TSa1b, FP-TBig1a, FP-TMa1a, and FP-TPC1a) based on the production of NIV in vitro were used. ${ }^{17}$ The fungal inoculum was produced by placing individual agar plugs with mycelium and conidia onto liquid medium containing carboxymethyl cellulose (CMC) for F. graminearum and potato dextrose agar (PDA) in Petri dishes $(90 \mathrm{~mm})$ for F. poae. For F. graminearum, $50 \mathrm{~mL}$ of CMC medium were placed in $250 \mathrm{~mL}$ Erlenmeyer flask and shaken continuously for 10 days (100 rpm, $25 \pm 2{ }^{\circ} \mathrm{C}$ and darkness). For $F$. poae the time of incubation was 7 days at $25 \pm 2^{\circ} \mathrm{C}$ under $12 \mathrm{~h}$ each of light and darkness. In this case, the conidial harvest was done by flooding the plates with $5 \mathrm{~mL}$ of sterilized distilled water (SDW) and dislodging the conidia with a bent glass rod. For both Fusarium species, the resulting suspension was filtered through cheesecloth and the conidial suspension was adjusted to $1 \times 10^{5}$ conidia/mL with a Neubauer hemacytometer. ${ }^{18}$ For each Fusarium species, the final conidial suspension was prepared with equal parts of each of the four isolates. Tween 20 $(0.05 \%)$ was added to the suspension as a surfactant.

Barley genotypes. Five genotypes of spring barley were evaluated: Scarlett (the genotype sown by most growers in Argentina, with excellent performance and malt quality), Shakira (second genotype in sowing area, for malting and with high yield potential), Andreia (new genotype, high screening percentage and malt quality), Scrabble 
(barley genotype for malting and with high yield potential) and INTA 7302 (two-row barley for malting or forage use). These genotypes were chosen because their times to harvest and rates of development through phenological stages were similar.

Experimental design. Field assays were carried out on the experimental farm at the Faculty of Agronomy, Azul, Buenos Aires province, Argentina (36 49'41.4" S, 59 53'11.6" W). The soil is a typical Argiudoll and the following are the characteristics of this soil at the depth of 0-20 cm: texture=clay loam soil, $\mathrm{pH}=6.06$ (1:2.5 in water), $\mathrm{N}$ nitrate=7.10 kg N/ha (reflectometry), available $\mathrm{P}=26.50 \mathrm{ppm}$, organic matter $=3.23 \%$. The field trials were repeated in 2014, 2015, and 2016 growing seasons. Conventional tillage practices were made with a disc plow and harrow to a depth of $15 \mathrm{~cm}$. Sowing dates ranged from 14 to 16 July in the three years because they were adjusted for the different genotypes to ensure uniformity in the timing of inoculation. Each plot size was $8 \times 1.5 \mathrm{~m}$ and genotypes were sown at 350 seeds $/ \mathrm{m}^{2}$. The distance between plots was $1 \mathrm{~m}$. Plants were grown in the absence of any nutritional or pest stress, without supplemental irrigation or fungicide treatments. Plants were fertilized with $150 \mathrm{~kg}$ N/ha, using urea (46\% nitrogen) in split doses at sowing and Z2.3. ${ }^{19}$ During crop cycle, insecticide (cypermethrin) were applied in the three years and weeds were removed by hand. Barley heads were inoculated when $>50 \%$ of the plants having undergone fertilization (Z.49) according to Buerstmayr. ${ }^{19,20}$ Conidial suspensions were applied until run-off using a hand-held garden sprayer ( 2 L), with adjustable brass nozzles. Plots were artificially inoculated by spraying $1 \mathrm{~L}$ of spore suspension (250 mL in each subplot). For control treatment, SDW with Tween $20(0.05 \%)$ was used to inoculate. The inoculum was 
applied: A) in the absence of wind, to limit the drift of the inoculum to neighbouring plots; B) in the evening on preferably cloudy days with high relative humidity (>80\%), to avoid the evaporation of the inoculum; C) keeping a distance between the nozzle and the spikes of around $5 \mathrm{~cm}$, to avoid spore dispersion. Furthermore, the plot to be inoculated was temporarily isolated from adjacent plots by placing $1.60 \mathrm{~m}$ plastic panels on the three sides of the plot and removing the panels when the inoculation was finished. To check the possibility of contamination with other Fusarium spp., 100 grains/subplot were selected at random, superficially disinfected (70\% ethanol for 2 min and 5\% sodium hypochlorite for $2 \mathrm{~min}$, then finally rinsed twice in SDW) and placed on PDA with 0.25 g of chloramphenicol and incubated for 7 days at $25 \pm 2{ }^{\circ} \mathrm{C}$ under $12 \mathrm{~h}$ each of light and darkness. Fusarium spp. were identified according to Leslie and Summerell. ${ }^{21}$ The field experiment was a split-plot design with four blocks, where the 20 treatments (five genotypes by two levels -presence or absence- of each Fusarium species) were applied for each block. Each plot sown with a genotype was divided into four subplots which were randomly assigned to one of the four inoculation combinations: 1) with $F$. graminearum alone $\left(\mathrm{FP}_{0} \mathrm{FG}_{1}\right)$, 2) with $F$. poae alone $\left(\mathrm{FP}_{1} \mathrm{FG}_{0}\right), 3$ ) with both pathogens ( $\left.\left.\mathrm{FP}_{1} \mathrm{FG}_{1}\right), 4\right)$ control without Fusarium species $\left(\mathrm{FP}_{0} \mathrm{FG}_{0}\right)$. Temperature, relative humidity, and precipitation data (from inoculation to harvest in 2014, 2015, and 2016) were obtained from the National Meteorological Center Weather Station located $100 \mathrm{~m}$ from the experimental site and from the Regional Center of Agrometeorology (RCA). 
Measurements. Visual disease assessment (incidence, severity, FHB Index) was conducted at 21 days post-inoculation by counting the number of symptomatic grains (lesions or bleaching of grains or glumes with a dark margin) of 40 spikes/plot selected at random according to Campbell and Lipps. ${ }^{22}$ After physiological maturity the plots were harvested, threshed and cleaned manually. Grain yield per plot $\left(\mathrm{g} / \mathrm{m}^{2}\right)$ was measured. Protein content and percentage of moisture were measured with a NIT analyzer with double-face monochromator (Agricheck, Bruins Instruments, Salem, NH, US ). The grains were sieved and the percentage of grains retained on a 2.5-mm sieve (screening percentage) were recorded. The germinative energy and the germinative power of seeds were evaluated according to ISTA rules for seed testing. ${ }^{23}$ The different fractions of hordeins were extracted from symptomatic/healthy grains by the method described by Salgado-Albarrán et al. ${ }^{4}$ All proteins were separated by SDS-PAGE (T=13.5\%). The gels were stained with 0.05\% Coomassie Brilliant Blue R250 for 24 h, distained in TCA 12\% for $48 \mathrm{~h}$ and finally washed in SWD for $24 \mathrm{~h}$. The resulting gels were scanned and analyzed by using TotalLab (v1.10 demo) software to measure the intensity of the pixel as an abundance indicator. Background subtraction was applied to avoid the variability due to the staining process. The contents of total hordein and D, C, B hordein fractions were determined. The toxins found in the grain samples were analyzed. About $200 \mathrm{~g}$ of seeds were taken, reduced to 25 g using a grain divider (Cereal Tools ${ }^{\circledR}$ ) and ground with a high speed disintegrator FW-110 (Arcano (); Pasteur Instrumental, Buenos Aires, Argentina). ${ }^{24}$ Trichothecenes were extracted for $1 \mathrm{~h}$ at $300 \mathrm{rpm}$ with $125 \mathrm{~mL}$ of acetonitrile:acetylacetate:water (50:41:9). The clean-up was performed with a column 
packed with charcoal:alumina:celite (0.7:0.5:0.3) and dried in a rotary evaporator. Gas chromatography, with 63Ni electron capture detection Shimadzu Model GC17 (Shimadzu Corp., Kyoto, Japan) equipped with split/splitless injector and fitted with RX-5MS capillary column (25 m x $0.2 \mathrm{~mm}$ id), was used to detect and quantify trichothecenes. The detection limits were $0.02 \mu \mathrm{g} / \mathrm{g}$ for DON and its acetyl derivatives and $0.05 \mu \mathrm{g} / \mathrm{g}$ for NIV, while the quantification limits were $0.06 \mu \mathrm{g} / \mathrm{g}$ for DON and $0.15 \mu \mathrm{g} / \mathrm{g}$ for NIV. Standards of DON, 3-ADON, 15-ADON and NIV were purchased from SIGMA Chemical Company (St Louis, MO, USA). The presence of compounds was confirmed by Gas Chromatography-Mass spectrometer system (GC-MS QP 5050A, Shimadzu®) with Electron Impact (EI) mode (70 eV) as described by Alvarez et al. ${ }^{25}$

Statistical analysis. All the variables evaluated were analyzed using the software R (v.3.3.3, R Core Team 2018). ${ }^{26}$ Due to the contrasting climatic conditions observed in the three growing seasons (mainly during the anthesis-harvest period), each year was evaluated separately. The main factor was the barley genotype and two levels (presence or absence) of each Fusarium species nested within the genotype, with 4 blocks for each combination of treatments. We used mixed-effects linear models, which allow nesting plots within blocks and subplots within plots. Data assumptions were verified graphically using plots of fitted values versus the residuals for homogeneity of variances and using normal Q-Q plots for normality of residuals. Furthermore, the Shapiro-Wilk test was used to check for normality of residuals. Protein concentration (PC), thousand kernel weight (TKW), grain yield (GY) and hordein fractions (D, C, and B-hordeins) were analyzed 
using the lmer function (lmer $\rightarrow$ variable $\sim F$. graminearum $* F$. poae * barley genotype + (1|block/bigplot), data=barley) (lme4 package $)^{27}$ with normal distribution of error. For mycotoxins analysis (DON, 3-ADON, 15-ADON and NIV) log transformation was performed $(\operatorname{lmer} \rightarrow \log ($ mycotoxin +1$) \sim F$. graminearum $*$ F. poae $*$ barley genotype + (1|block/bigplot), data=barley). The variables incidence (I), severity (S), FHB Index, germinative energy (GE), germinative power (GP) and screening percentage (SP) were analyzed with a generalized linear mixed model (glmer $\rightarrow$ variable (cbind) $\sim F$. graminearum $*$ F. poae $*$ barley genotype $+(1$ block/bigplot $)$, family $=$ binomial (link $=$ "logit"), data = barley) that considered the restrictions in the randomization and non normal errors with the function glmer (lme4 package). ${ }^{27}$ In all cases, a full model including all interactions was analyzed and significance was tested with Type II Likelihood Ratio Test. Significant of effects were tested with the lsmeans function (emmeans package) ${ }^{28}$ Results were reported as the mean \pm standard error of the mean (SEM) for all the variables analyzed, except for mycotoxins contamination that was reported as mean \pm SEM of the log transformed data.

\section{Results}

Climatic conditions. The environmental conditions in the three years were different particularly in the flowering stage. In 2014, the average temperature was the highest $\left(18.22 \pm 3.71^{\circ} \mathrm{C}\right)$ being the warmest and wettest year $(209.60 \mathrm{~mm}, 67.24 \pm 11.55 \%$ RH), favorable for growth conditions for Fusarium spp. In contrast, in 2015 and 2016 growing seasons the weather conditions were not optimal for the development of the 
disease (Table 1). The spring of 2015 had the lowest minimum temperatures $(9.88 \pm 4.08$ $\left.{ }^{\circ} \mathrm{C}\right)$ with less rainfall than $2014(144.60 \mathrm{~mm}, 68.88 \pm 11.17 \% \mathrm{RH})$, while the spring of 2016 was the driest with low rainfall and less relative humidity $(74.90 \mathrm{~mm}, 59.79 \pm$ 13.07\% RH) with moderate temperatures (17.62 $\left.\pm 3.88{ }^{\circ} \mathrm{C}\right)$. Regarding historical precipitation for the anthesis-harvest period, in 2014 we registered an increase of 27\%, while contrarily in 2015 and 2016 we observed a decrease in the precipitation (12\% and 55\%, respectively) (Table 1).

Disease parameters. Significant differences $(\mathrm{p}<0.05, \mathrm{n}=80)$ were detected only for incidence and severity parameters in 2014, but not for 2015 and 2016 growing season (Fig. 1). In addition, all genotypes showed symptoms with all the isolates used as inoculum. Regarding incidence $(\mathrm{p}=0.0055, \mathrm{n}=80$ ), effects of the Fusarium treatments were observed only in 2014 (Fig. 1A) showing the highest values for $\mathrm{FP}_{1} \mathrm{FG}_{1}$ treatment $(58.00 \pm 6.00 \%)$ followed by $\mathrm{FP}_{0} \mathrm{FG}_{1}(50.00 \pm 5.00 \%)$ and $\mathrm{FP}_{1} \mathrm{FG}_{0}(46 \pm 6.00 \%)$. In the same way, severity was significantly differences $(\mathrm{p}<0.0005, \mathrm{n}=800)$ in 2014 for Fusarium treatments (Fig. 1B), being the most affected $\mathrm{FP}_{1} \mathrm{FG}_{1}$ and $\mathrm{FP}_{0} \mathrm{FG}_{1}(3.00 \pm 0.23 \%)$ followed by $\mathrm{FP}_{0} \mathrm{FG}_{1}(2.80 \pm 0.23 \%)$ and $\mathrm{FP}_{1} \mathrm{FG}_{0}(2.00 \pm 0.23 \%)$.

On the other hand, in 2015 only significant differences $(p<0.0010, n=80)$ were observed among different genotypes for incidence, being Shakira (29.00 $\pm 3.00 \%)$, Andreia (23.00 $\pm 3.00 \%)$ and INTA $7302(21.00 \pm 3.00 \%)$ the most affected genotypes, while Scrabble $(8.00 \pm 2.00 \%)$ and Scarlett $(6.00 \pm 2.00 \%)$ showed the lowest symptoms (Fig. 1D). In the same way, for severity only significant differences $(p<0.0001, n=800)$ 
were found among the different genotypes being Shakira (5.80 $\pm 0.26 \%)$ the most affected genotype, while in Scrabble (0.30 $\pm 0.09 \%)$ the lowest values of severity were observed (Fig. 1E). Although the values were low, for FHB Index significant differences were observed $(p=0.0012, n=80)$, being Shakira the most affected $(2.30 \pm 0.70)$, while Scrabble $(0.10 \pm 0.03)$ and Scarlett $(0.10 \pm 0.01)$ showed the lowest values (Fig. $1 \mathrm{~F})$.

Germination and grain quality parameters. Significant differences were observed only for Fusarium treatments in parameters such as GE, GP, and SP depending on the genotype, while there were no effects on PC (Table 2). For yield parameters as TKW and GY, there were only significant differences for genotype.

Regarding GE, in 2014 significant differences were found $(\mathrm{p}<0.0001, \mathrm{n}=60)$ for Fusarium $\mathrm{x}$ genotype interaction, showing for $\mathrm{FP}_{0} \mathrm{FG}_{1}$ that Andreia was not affected $(85.00 \pm 3.00 \%)$, while Shakira (83.00 to $71.00 \%)$ was the most affected, with a decrease of $12.00 \%$ in relation to $\mathrm{FP}_{0} \mathrm{FG}_{0}$. In contrast, in 2015 and 2016 growing seasons significant differences were found $\left(\mathrm{p}<0.0001, \mathrm{n}=80\right.$ ) for the interaction of the $\mathrm{FP}_{1} \mathrm{FG}_{0} \mathrm{x}$ genotype. In 2015, Scarlett was the least affected genotype reducing GE by 2.00\% (94.00 to $92.00 \%$ ) while Andreia was the most affected with a loss of $11.00 \%$ (65.00 to $54.00 \%)$. In addition, Scarlett remained the least affected genotype in 2016, losing 2.00\% (94.00 to 92.00\%), while INTA 7302 was the most affected genotype with a loss of $8.00 \%$ (93.00 to $85.00 \%)$.

On the other hand, GP was affected in 2014 by the $\mathrm{FP}_{1} \mathrm{FG}_{1} \mathrm{x}$ genotype interaction ( $p=0.0048, n=60)$, being Andreia the least affected losing 2.00\% (92.00 to 90.00\%), while 
a decrease of 6.00\% was observed in INTA 7302 (90.00 to 84.00\%). In addition, in 2015 and 2016 there were significant differences $(\mathrm{p}<0.0001$, $\mathrm{n}=80)$ for the $\mathrm{FP}_{1} \mathrm{FG}_{0} \mathrm{x}$ genotype interaction. In 2015, Scarlett was the least affected genotype, reducing only by $2.00 \%$ (98.00 to $96.00 \%$ ), while a reduction of $11.00 \%$ was observed in Andreia (83.00 to 72.00\%). In the same way, in 2016 Scarlett was the least affected genotype losing only $2.00 \%$ (97.00 to $95.00 \%)$, while the greatest decreases (7.00\%) were observed in INTA 7302 (97.00 to $90.00 \%)$.

Regarding SP, in 2014 only significant differences were observed for genotype, showing Shakira the highest values (96.75 $\pm 0.59 \%)$ and INTA 7302 the lowest values (90.30 $\pm 1.35 \%)$. On the other hand, in $2015 \mathrm{FP}_{1} \mathrm{FG}_{1} \mathrm{x}$ genotype interaction was observed, showing the highest values of SP for Shakira $x \mathrm{FP}_{0} \mathrm{FG}_{0}(97.55 \pm 0.50 \%)$ while the lowest values were reported for INTA $7302 \times \mathrm{FP}_{1} \mathrm{FG}_{1}(94.73 \pm 0.76 \%)$. In 2016, F. poae $\mathrm{x}$ genotype interaction showed significant differences, being Shakira the genotype most affected, decreasing the SP in $0.62 \%$ respect to the control.

As to grain yield parameters such as TKW and GY, there were significant differences only for genotype. In contrast, for PC there were no significant differences in any of the years evaluated (Table 2). For TKW in 2014 and 2015, Scrabble had the heaviest grain (41.64 and $51.51 \mathrm{~g}$, respectively) while the lower grain weights were found in Scarlett (34.69 and $42.27 \mathrm{~g}$, respectively). In the same way, for GY the lowest values were reported in Scarlett $\left(478.81 \pm 32.75 \mathrm{~g} / \mathrm{m}^{2}\right)$, while Andreia showed the highest grain yield $\left(611.56 \pm 32.75 \mathrm{~g} / \mathrm{m}^{2}\right)$. 
Protein composition. The analysis of protein fractions was performed only in 2014, due to the favorable conditions for FHB development. Significant differences were found for Fusarium treatments, showing degradation of the different hordeins fractions with respect to the control (Table 3, Fig. 2). For D-hordeins, the highest decrease in relative abundance were observed in $\mathrm{FP}_{0} \mathrm{FG}_{1}$ treatment decreasing by $83.41 \%$ compared to the control, while a decrease of $81.24 \%$ on average was observed for $\mathrm{FP}_{1} \mathrm{FG}_{0}$ and $\mathrm{FP}_{1} \mathrm{FG}_{1}$. In the same way, for $\mathrm{C}$-hordeins the lowest values were observed in $\mathrm{FP}_{0} \mathrm{FG}_{1}$ decreasing by $82.35 \%$ with respect to $\mathrm{FP}_{0} \mathrm{FG}_{0}$, while for $\mathrm{FP}_{1} \mathrm{FG}_{0}$ and $\mathrm{FP}_{1} \mathrm{FG}_{1}$ a decrease of $79.46 \%$ on average was reported. On the other hand, the greatest degradation in Bhordeins fraction was caused by $\mathrm{FP}_{1} \mathrm{FG}_{1}$ treatment, being $50.25 \%$ lower than the control, while a decrease of $39.07 \%$ on average was observed in $\mathrm{FP}_{1} \mathrm{FG}_{0}$ and $\mathrm{FP}_{0} \mathrm{FG}_{1}$ treatments. Regarding the total hordeins content, the lowest values of relative abundance were found in $\mathrm{FP}_{1} \mathrm{FG}_{1}$ treatment being $68.55 \%$ lower than $\mathrm{FP}_{0} \mathrm{FG}_{0}$, while for $\mathrm{FP}_{1} \mathrm{FG}_{0}$ and $\mathrm{FP}_{0} \mathrm{FG}_{1} \mathrm{a}$ decrease of $66.66 \%$ on average was observed.

Mycotoxin contamination. Regarding the possible antagonism/synergism interaction between the mycotoxins accumulation of $F$. graminearum and $F$. poae treatments, no significant differences were observed in all the years analyzed. In 2014, the highest mycotoxin value was observed in $\mathrm{FP}_{0} \mathrm{FG}_{1}$ treatment, with high concentrations of DON (6.12 $\pm 1.77 \mu \mathrm{g} / \mathrm{g})$ and 15-ADON (1.21 $\pm 0.05 \mu \mathrm{g} / \mathrm{g})$, while the 3-ADON and NIV production was higher in $\mathrm{FP}_{1} \mathrm{FG}_{1}$ treatment $(21.60 \pm 11.41$ and $1.20 \pm 0.06 \mu \mathrm{g} / \mathrm{g}$, respectively). In 2015 and 2016, mycotoxin values were lower compared to 2014 and 
NIV production was not detected. In 2015, the major amounts of mycotoxins were observed for $\mathrm{FP}_{0} \mathrm{FG}_{1}\left(\mathrm{DON}: 1.53 \pm 0.11 \mu \mathrm{g} / \mathrm{g}\right.$ ) and $\mathrm{FP}_{1} \mathrm{FG}_{1}$ treatments (3-ADON: $5.20 \pm$ $1.29 \mu \mathrm{g} / \mathrm{g} ; 15-A D O N$ : $1.41 \pm 0.11 \mu \mathrm{g} / \mathrm{g})$. In the same way, in 2016 the highest values of mycotoxins were registered in $\mathrm{FP}_{0} \mathrm{FG}_{1}$ treatment, with low concentrations of DON (1.02 $\pm 0.002 \mu \mathrm{g} / \mathrm{g})$ and 3-ADON $(2.58 \pm 0.30 \mu \mathrm{g} / \mathrm{g})$, while for 15-ADON $(1.41 \pm 0.11 \mu \mathrm{g} / \mathrm{g})$ the highest values were observed in $\mathrm{FP}_{1} \mathrm{FG}_{1}$ treatment. In terms of total mycotoxin amount, we found a higher concentration of 3-ADON over the years evaluated (Table 4).

\section{Discussion}

The experiment was carried out under field conditions, being the three years analyzed different from each other, mainly with respect to environmental conditions such as relative humidity, temperature, and accumulated rainfall during the period from anthesis to harvest. Our results showed significant differences between the Fusarium treatments in disease parameters only in the 2014 growing season, with warm temperatures and wet conditions that were favorable especially for the growth of $F$. graminearum. On the other hand, in 2015 and 2016 no statistical differences were observed in disease parameters, due to the lowest temperatures and the driest conditions at the flowering stage. Several authors found evidence indicating that environmental conditions play a key role in Fusarium spp.-host interactions. Moreover, the composition of Fusarium species changes according to the effects of different climatic factors on each growing season, mainly during the flowering stage. ${ }^{29}$ Turner \& Jennings ${ }^{30}$ observed that 
increasing humidity produced earlier disease development and a major incidence of the disease for all Fusarium species evaluated except to F. poae. The variations in the composition of the Fusarium species can be explained by the occurrence of different thermo-hygrometric conditions, and when the conditions were not favorable for the main causal agents of FHB such as F. graminearum and F. culmorum, other species as F. poae and $F$. avenaceum significantly increase their presence. In general, warm temperatures (around $28^{\circ} \mathrm{C}$ ) and wet conditions are favorable for F. graminearum infection, while temperatures around $25^{\circ} \mathrm{C}$ and dry conditions are for $F$. poae. ${ }^{15,31 .}$ In addition, it is known that genotype plays an important role in FHB resistance. In our work, in 2015 different responses were observed to Fusarium spp. infection among different barley genotypes. Although the barley genotypes were chosen for their similar phenological stages, these results could be explained by slight differences in temporal and spatial flowering patterns, the different micro-environment and microclimatic conditions combined of each trial plot, and the possibility of resistance genes present in different barley genotypes.

Previously studies reported a decrease in kernel plumpness, low values of kernels larger than $2.5 \mathrm{~mm}$ in diameter and a slight increase in protein and total nitrogen content in inoculated barley grains. ${ }^{7,32}$ In the current study, we observed Fusarium x genotype interaction for the screening percentage (2015 and 2016), while there were no significant differences among Fusarium treatments on protein concentration and thousand kernel weight. These effects showed a significant effect mainly of the genotype, being consistent with other works that describe a strong genetic and environmental influence on the differences in the parameters analyzed on barley genotypes. ${ }^{33,34}$ 
Regarding germinative parameters, several studies have revealed that the growth of Fusarium spp. may affect germination capacity and therefore malt characteristics. Furthermore, Fusarium spp. can produce other undetected proteinases during the infection, and can trigger the synthesis or activation of some barley proteinases that normally function during the germination process. ${ }^{8}$ According to this, Schwarz et al. ${ }^{32}$ reported a decrease from $42.00 \%$ to $32.00 \%$ in barley infected with F. graminearum and a decrease from $14.00 \%$ to $8.00 \%$ in treatments inoculated with $F$. poae. In the same way, Sarlin et al. ${ }^{7}$ observed a reduction of $10.00 \%$ on average using a mixture of Fusarium species, while Oliveira et al. ${ }^{35}$ found a decrease around $45.00 \%$ in germinative energy by inoculating with F. culmorum. Results observed in our work agree with those previously reported, showing that in 2014 highest effects on GE/GP were observed for $F$. graminearum treatment decreasing by 6.00\% on average, while in 2015 and 2016 growing season $F$. poae affected both parameters depending on the genotype, reducing by $4.00 \%$ on average.

Fusarium spp. infection may lead to the production of different hydrolytic enzymes such as cutinases, proteinases, xylanases, and cellulases. These cell walldegrading enzymes could play an important role in pathogenicity and are likely to be involved in the colonization of barley grains, being the proteinases the most important, therefore protein degradation can strongly affect the malting or brewing quality of the diseased grain. ${ }^{8,32}$ In our work, we reported a slight trend in symptomatic barley grains showing that F. graminearum presence degraded a great amount of hordeins, around 83.41\% and 82.35\% in D-hordeins and C-hordeins, respectively. Furthermore, we 
reported a decrease caused by $F$. graminearum x $F$. poae treatment $\left(F P F_{1} \mathrm{G}_{1}\right)$ of $50.25 \%$ in B-hordeins and a reduction of the total hordeins content in $68.55 \%$ respect to the control. Changes observed in hordeins fraction could be explained due to fungal proteases activity such as trypsin protease or serine protease that belongs to the exoproteome of Fusarium spp. known as protein-degrading enzymes. ${ }^{8,9}$ Eggert et al. ${ }^{36}$ found that the influence of Fusarium infection on naked barley reduced slightly the content of hordeins, while the albumins and globulins were not affected. In addition, Schwarz et al. ${ }^{32}$ detected the higher proteinase, $\beta$-glucanase, and xylanase activity levels in barley samples artificially infected with F. graminearum and F. poae compared with the control, concluding that enzyme activity levels in barley samples were so high that they might affect the grain quality and therefore malt quality. Regarding the potential impact on malt quality, several authors have reported that heavy Fusarium spp. infection decreases $\beta$ glucan content and simultaneously increases soluble nitrogen, free amino nitrogen (FAN) and wort color, suggesting that Fusarium proteinases could degrade barley proteins already in the field or during malting and mashing. ${ }^{7}$

Based on the major values of incidence/severity in the field during 2014, we expected a higher mycotoxin concentration in this year compared to 2015 and 2016. Mycotoxin concentration varied greatly between Fusarium treatments, genotypes and years, observing the highest amount of DON in 2014 for F. graminearum treatment (Table 4). For DON, these values were above the maximum limits established by the European Commission for unprocessed grains $(1.25 \mu \mathrm{g} / \mathrm{g}) .{ }^{14}$ Moreover, we found an 
important concentration of 3-ADON in the different years evaluated, which coincides with our results obtained in bread wheat. ${ }^{37}$

In some studies, the predominant toxin is NIV which is believed to be more toxic than DON or its acetylated derivatives, although the maximum limit for NIV has not been established yet. ${ }^{38}$ The Scientific Committee on Food (SCF) has set limits only for DON, considering a tolerable daily intake of $1 \mathrm{mg} / \mathrm{kg}$ body weight, while for NIV, a provisional limit value of $0.7 \mathrm{mg} / \mathrm{kg}$ was established. ${ }^{14}$ Stenglein et al. ${ }^{39}$ found higher levels of NIV in barley genotypes inoculated under field conditions (ranging between 0.20 and 10.80 $\mu \mathrm{g} / \mathrm{g}$ ), while Nogueira et al. ${ }^{40}$ found NIV in $29 \%$ of the barley samples evaluated (with an average concentration of $2.36 \mu \mathrm{g} / \mathrm{g}$ ) under natural infection conditions. In the present study, we reported lower values that could be explained due to the climatic conditions (mainly temperature) during the flowering stage. These climatic conditions were not optimal to the development of $F$. poae and the subsequent NIV production. This is supported by Nazari et al. ${ }^{31}$, who established that the optimum temperature for F. poae growth is $24.7^{\circ} \mathrm{C}$ and for NIV production $27.5^{\circ} \mathrm{C}$.

Scarce information about Fusarium species interaction and their potential impact in mycotoxin production are available. Xu et al. ${ }^{41}$ reported that there was no evidence to support synergism between fungal isolates in causing visual symptoms; thus suggesting the existence of competitive interactions that led to decrease in the fungal biomass (until 90\% for weaker species) compared to single-isolate inoculations. Regarding mycotoxin contamination, reports in co-inoculation experiments indicate that the productivity increased considerably (in many cases exceeding 100-fold) suggesting that competition 
resulted in greater production of trichothecene mycotoxins. ${ }^{41}$ This effect on mycotoxin production in co-inoculations could be explained by competition between Fusarium species which produces more toxin under stress conditions as resources for competence. ${ }^{15}$ In the present work, no significant differences were observed between Fusarium treatments. However, we found a major concentration of 3-ADON along the different years, despite the fact that the F. graminearum isolates used were DON, 3-ADON and 15-ADON producers. This prevalence of 3-ADON biosynthesis could be explained by the important role that plays some climatic parameters such as the temperature and other environmental conditions. ${ }^{42}$ In accordance with this, Ramírez Albuquerque et al. ${ }^{43}$ found under in vitro conditions a major production of DON acetylated derivatives, being the production of $3-\mathrm{ADON}$ maximum at $25-30^{\circ} \mathrm{C}$, while the production of $15-\mathrm{ADON}$ is maximum at $10^{\circ} \mathrm{C}$.

\section{Conclusions}

This is the first work under field conditions during three growing seasons evaluating the interaction between $F$. graminearum and F. poae on barley genotypes. We conclude that: 1 ) no evidence of synergism between $F$. graminearum and $F$. poae were found regarding disease parameters and mycotoxin contamination; 2) coinciding with previous works, different response patterns to Fusarium infection exists between barley genotypes, that could be useful for future genetic improvement; 3) depending on the genotype, the germination process was affected by both Fusarium species ( $F$. graminearum $>$ F. poae) which could affect the protein composition, the malt quality and 
therefore the malting process 4 However, at least in the years with favorable climatic conditions to FHB development and depending on the barley genotype, a continuous monitoring is deemed necessary to prevent the negative impact on protein composition and germinative parameters

\section{Acknowledgments}

We thank the Wheat Industrial Quality Laboratory-UNCPBA, Mendivil, G., Troncoso, U., and Pacheco, W. for technical assistance in field experiments. This research was carried out with the following funds: FONCyT-PICT 213/2015 and UNCPBA.

\section{Conflict of interest}

The authors declare no have conflict of interest.

\section{References}

1.Schwarz PB, Horsley RD, Steffenson BJ, Salas B, Paul S, Barr JM, Quality risks associated with the utilization of Fusarium head blight infected malting barley. $J$ Am Soc Brew Chem 1:1-7 (2006).

2-Norma V- Cebada cervecera y forrajera, Available at: https://cacbb.com.ar/normativa/estandares/Norma\%20V\%20\%20Cebada\%20Cervecera\%20y\%20Forrajera-\%20R\%20SENASA\%20272013\%20-\%20A\%20partir\%20de\%20Oct\%202014.pdf (2013). 
3.USDA, Available at: https://www.fas.usda.gov/data/argentina-grain-and-feedupdate-7 (2018).

4.Salgado-Albarrán M, Herrera-Díaz J, Dinkova TD, Caracterización de patrones de hordeínas en variedades mexicanas de cebada maltera. TIP Rev Esp Cienc QuímBiol 18:43-51 (2015).

5.Qi JC, Chen JX, Wang JM, Wu FB, Cao LP, Zhang GP, Protein and hordein fraction content in barley seeds as affected by sowing date and their relation to malting quality. J Zhejiang Univ Sci B 6:1069-1075 (2005).

6.Nielsen LK, Cook DJ, Edwards SG, Ray RV, The prevalence and impact of Fusarium head blight pathogens and mycotoxins on malting barley quality in UK. Int J Food Microbiol 179:38-49 (2014).

7.Sarlin T, Laitila A, Pekkarinen A, Haikara A, Effects of three Fusarium species on the quality of barley and malt. J Ame Soc Brew Chem 63:43-49 (2005).

8-Pekkarinen AI, Sarlin TH, Laitila AT, Haikara AI, Jones BL, Fusarium species synthesize alkaline proteinases in infested barley. J Cereal Sci 37:349-356 (2003).9.Phalip V, Delalande F, Carapito C, Goubet F, Hatsch D, Leize-Wagner E, Diversity of the exoproteome of Fusarium graminearum grown on plant cell wall. Curr Genet 48: 366-379 (2005).

10.Placinta CM, D’Mello JPF, MacDonald, AMC, A review of worldwide contamination of cereal grains and animal feed with Fusarium mycotoxins. Anim Feed Sci Technol 78: 21-37 (1999).

11.Papadoupoulou-Bouraoui A, Vrabcheva T, Valzacchi S, Stroka J, Anklam E, 
Screening survey of deoxynivalenol in beer from the European market by an enzyme-linked immunosorbent assay. Food Addit Contam 21:607-617 (2007).

12.Nagashima H, Nakagawa H, Kushiro M, The in vitro approach to the cytotoxicity of a trichothecene mycotoxin nivalenol. Jpn Agr Res Q JARQ 43:7-11 (2009).

13.Bryla M, Ksieniewicz-Wozniak E, Waskiewicz A, Szymczyk K, Jedrezjczak R, Cooccurrence of nivalenol, deoxynivalenol and deoxynivalenol-3-glucoside in beer samples. Food Control 92: 319-324 (2018).

14.European Commission, Commission Regulation no 1881/2006 of 19 December 2006 setting maximum levels for certain contaminants in foodstuff. OJ Eur Union 364: 5-24 (2006).

15.Xu X, Nicholson P, Community ecology of fungal pathogens causing wheat head blight. Annu Rev Phytopathol 47:83-103 (2009).

16.Castañares E, Albuquerque DR, Dinolfo MI, Fernández Pinto V, Patriarca A, Stenglein SA, Trichothecene genotypes and production profiles of Fusarium graminearum isolates obtained from barley cultivated in Argentina. Int J Food Microbiol 179: 57-63 (2014).

17.Dinolfo I, Barros G, Stenglein S, Development of a PCR assay to detect the potential production of nivalenol in Fusarium poae. FEMS Microbiol Lett 332: 99104(2012).

18.Brennan JM, Egan D, Cooke BM, Doohan FM, Effect of temperature on head blight of wheat caused by Fusarium culmorum and F. graminearum. Plant Pathol 54: 156-160 (2005). 
19.Zadoks JC, Chang TT, Konzak CF. A decimal code for the growth stages of cereals. Weed Res, 14: 415-421 (1974).

20.Buerstmayr H, Legzdina L, Steiner B, Lemmens M, Variation for resistance to Fusarium head blight in spring barley. Euphytica 137:279- 290 (2004).

21.Leslie JF, Summerell BA, The Fusarium Laboratory Manual. Oxford, UK, Blackwell Publishing (2006).

22.Campbell KA,Lipps PE, Allocation of resources: sources of variation in Fusarium Head Blight screening nurseries. Phytopathology 88:1078-1086 (1998).

23.ISTA, International Rules for Seed Testing. The international Seed Testing Association (ISTA). Zürichstr. 50, CH-8303 Bassersdorf, Switzerland (2017).

24.Martínez M, Castañares E, Dinolfo MI, Pacheco WG, Moreno MV, Stenglein SA, Presencia de Fusarium graminearum en muestras de trigo destinado al consumo humano. Rev Argent Microbiol 46:41-44 (2014).

25.Alvarez CL, Azcarate MP, Fernández Pinto V, Toxigenic potential of Fusarium graminearum sensu stricto isolates from wheat in Argentina. Int J Food Microbiol 135: 131-135 (2009).

26.R Core Team. R: A language and environment for statistical computing. R Foundation for Statistical Computing, Vienna, Austria. URL https://www.R-project.org/ (2017)

27.Bates D, Maechler M, Bolker B, Walker S, Fitting linear mixed-effects models using lme4. J Stat Softw 67:1-48 (2015). 
28.Lenth RV, emmeans: estimated marginal means, a.k.a. least-squares means. R package version 1.3.0. [https://CRAN.R-project.org/package=emmeans] (2018).

29.Vogelgsang S, Sulyok M, Hecker A, Jenny E, Krska R, Schuhmacher R, Toxigenicity and pathogenicity of Fusarium poae and Fusarium avenaceum on wheat. Eur J Plant Pathol 122: 265-276 (2008).

30.Turner JA, Jennings $P$, The effect of increasing humidity on Fusarium ear blight and grain quality. Cereal Re Commun 25: 825-826 (1997).

31.Nazari L, Pattori E, Manstretta V, Terzi V, Morcia C, Somma S, Moretti A, Ritieni A, Rossi V, Effect of the temperature on growth, wheat head infection, and nivalenol production by Fusarium poae. Food Microbiol 76:83-90 (2018).

32.Schwarz PB, Jones BL, Steffenson BJ, Enzymes associated with Fusarium infection of barley. J Ame Soc Brew Chem 60:130-134 (2002).

33.Al-Tabbal JA, Al-Fraihat A, Genetic variation, heritability, phenotypic and genotypic correlation studies for yield and yield components in promising barley genotypes. J Agric Sci 4:193-210 (2011).

34.Cai S, Yu G, Chen X, Huang Y, Jiang X, Zhang G, Xioli J, Grain protein content variation and its association analysis in barley. BMC Plant Biol 1:13-35 (2013).

8.

35. Oliveira PM, Mauch A, Jacob F, Waters DM, Arendt EK, Fundamental study on the influence of Fusarium infection on quality and ultrastructure of barley malt. Int $J$ Food Microbiol 156:32-43 (2012).

36.Eggert K, Wieser H, Pawelzik E, The influence of Fusarium infection and growing 
location on the quantitative protein composition of (Part II) naked barley (Hordeum vulgare nudum). Eur Food Res Technol 230: 893-902 (2010).

37. Martínez M, Ramírez Albuquerque LD, Arata AF, Biganzoli F, Fernández Pinto V, Stenglein SA, Effects of Fusarium graminearum and Fusarium poae on disease parameters, grain quality and mycotoxins contamination in bread wheat (Part I). J Sci Food Agric (In press).

38.Wan MYL, Turner PC, El-nezami H, Individual and combined cytotoxic effects of Fusarium toxins (deoxynivalenol, nivalenol, zearalenone and fumonisins B1) on swine jejunal epithelial cells. Food Chem Toxicol 57:276-283 (2013).

39.Stenglein S, Dinolfo I, Barros G, Bongiorno F, Chulze S, Moreno V, Fusarium poae: pathogenicity and mycotoxin accumulation on selected wheat and barley genotypes at a single location in Argentina. Plant Dis 98:1733-1738 (2014).

40.Nogueira M, Decundo J, Martínez M, Dieguez S, Moreyra F, Moreno M, Stenglein SA, Natural contamination with mycotoxins produced by Fusarium graminearum and Fusarium poae in malting barley in Argentina. Toxins 10, 78 (2018).

41.Xu XM, Monger W, Ritieni A, Nicholson P, Effect of temperature and duration of wetness during initial infection periods on disease development, fungal biomass and mycotoxin concentrations on wheat inoculated with single, or combinations of, Fusarium species. Plant Pathol 56:943-956 (2007).

42. SugiuraY,WatanabeY,TanakaT, YamamotoS and UenoY, Occurrence of Gibberella zeae strains that produce both nivalenol and deoxynivalenol. Appl Environ Microbiol 56:3047-3051 (1990). 
43Ramirez Albuquerque $L D$, Influence of environmental factors in the relative production of tricothecenes by Fusariumgraminearum. MSc thesis, Universidad de Buenos Aires. Facultad de Ciencias Exactas y Naturales (2014). http://hdl.handle.net/20.500.12110/tesis_n5609_RamirezAlbuquerque 
Table 1. Mean values and standard deviation of temperature, relative humidity (RH), and accumulated precipitation during 2014, 2015, and 2016 growing seasons (from inoculation to harvest) ${ }^{\mathrm{a}}$.

\begin{tabular}{|c|c|c|c|c|c|c|c|}
\hline \multirow{2}{*}{ Year } & \multicolumn{3}{|c|}{ Temperature $\left({ }^{\circ} \mathrm{C}\right)$} & \multirow{2}{*}{$\begin{array}{c}\text { RH\% } \\
\text { (average) }\end{array}$} & \multirow{2}{*}{$\begin{array}{c}\text { Accumulated } \\
\text { precipitation } \\
(\mathbf{m m})\end{array}$} & \multirow{2}{*}{$\begin{array}{c}\text { Historical } \\
\text { precipitation } \\
(\mathbf{m m})\end{array}$} & \multirow{2}{*}{$\begin{array}{l}\text { \% Precipitation } \\
\text { Variation }\end{array}$} \\
\hline & Average & $\begin{array}{c}\text { Average } \\
\text { minimum }\end{array}$ & $\begin{array}{c}\text { Average } \\
\text { maximum }\end{array}$ & & & & \\
\hline 2014 & $18.22 \pm 3.71$ & $11.64 \pm 3.52$ & $25.19 \pm 4.87$ & $67.24 \pm 11.55 \%$ & 209.60 & & $+27 \%$ \\
\hline 2015 & $17.65 \pm 3.06$ & $9.88 \pm 4.08$ & $24.97 \pm 3.75$ & $66.88 \pm 11.17 \%$ & 144.60 & 165.10 & $-12 \%$ \\
\hline
\end{tabular}

Weather station was located $100 \mathrm{~m}$ from the experimental site and data were taken every $30 \mathrm{~min}$. 
Table 2. Analysis of variance for different grain parameters. GE: germinative energy; GP: germinative power; PC: protein concentration; SP: screening percentage; TKW: thousand kernel weight; d.f.: degrees of freedom; Chisq: Type II Wald Chi-square tests.

\begin{tabular}{|c|c|c|c|c|c|c|c|c|c|c|c|}
\hline \multirow{3}{*}{ Source } & \multicolumn{11}{|c|}{2014} \\
\hline & \multirow[b]{2}{*}{ d.f } & \multicolumn{2}{|c|}{ GE } & \multicolumn{2}{|c|}{ GP } & \multicolumn{2}{|c|}{ PC } & \multicolumn{2}{|c|}{ SP } & \multicolumn{2}{|c|}{ TKW } \\
\hline & & Chisq & p-value & Chisq & p-value & Chisq & p-value & Chisq & p-value & Chisq & p-value \\
\hline F. poae $(\mathrm{FP})$ & 1 & 0.10 & 0.75 & 1.81 & 0.18 & 0.18 & 0.67 & 0.023 & 0.87 & 0.0522 & 0.82 \\
\hline F. graminearum (FG) & 1 & 11.47 & $<0.0001$ & 16.41 & $<0.0001$ & 0.14 & 0.71 & 0.30 & 0.58 & 0.7934 & 0.37 \\
\hline $\mathrm{FP} * \mathrm{FG}$ & 1 & 2.03 & 0.16 & 4.70 & 0.26 & 0.38 & 0.54 & 1.25 & 0.26 & 0.8556 & 0.36 \\
\hline Genotype (G) & 4 & 2.26 & 0.69 & 5.25 & 0.03 & 3.64 & 0.46 & 20.02 & 0.0005 & 23.2228 & $<0.0001$ \\
\hline FP x G & 4 & 3.71 & 0.45 & 9.52 & 0.05 & 6.16 & 0.19 & 0.89 & 0.93 & 1.1394 & 0.89 \\
\hline FG x G & 4 & 32.31 & $<0.0001$ & 25.92 & $<0.0001$ & 0.51 & 0.97 & 1.08 & 0.90 & 1.6520 & 0.80 \\
\hline \multirow[t]{2}{*}{$F P \times F G \times G$} & 4 & 4.19 & 0.38 & 14.91 & 0.01 & 4.84 & 0.31 & 3.54 & 0.47 & 3.9729 & 0.41 \\
\hline & \multicolumn{11}{|c|}{2015} \\
\hline F. poae (FP) & 1 & 0.17 & 0.68 & 5.24 & 0.02 & 2.43 & 0.12 & 0.05 & 0.83 & 2.0318 & 0.15 \\
\hline F. graminearum (FG) & 1 & 1.17 & 0.28 & 0.53 & 0.47 & 0.81 & 0.37 & 0.42 & 0.52 & 1.6586 & 0.20 \\
\hline $\mathrm{FP} * \mathrm{FG}$ & 1 & 0.85 & 0.36 & 1.80 & 0.18 & 0.89 & 0.35 & 0.01 & 0.93 & 0.0400 & 0.84 \\
\hline Genotype (G) & 4 & 21.76 & $<0.0001$ & 186.60 & $<0.0001$ & 9.42 & 0.05 & 8.09 & 0.09 & 151.3667 & $<0.0001$ \\
\hline $\mathrm{FP} \times \mathrm{G}$ & 4 & 34.19 & $<0.0001$ & 49.82 & $<0.0001$ & 3.27 & 0.51 & 0.68 & 0.95 & 3.2791 & 0.51 \\
\hline FG x G & 4 & 2.77 & 0.60 & 2.35 & 0.67 & 2.86 & 0.58 & 0.95 & 0.92 & 2.0991 & 0.72 \\
\hline \multirow[t]{2}{*}{$F P \times F G \times G$} & 4 & 3.37 & 0.50 & 3.88 & 0.42 & 4.04 & 0.40 & 11.42 & 0.02 & 1.0364 & 0.90 \\
\hline & \multicolumn{11}{|c|}{2016} \\
\hline F. poae (FP) & 1 & 5.15 & 0.02 & 4.88 & 0.03 & 1.76 & 0.18 & 0.77 & 0.38 & 0.0021 & 0.96 \\
\hline F. graminearum $(\mathrm{FG})$ & 1 & 7.21 & 0.01 & 10.10 & 0.002 & 1.85 & 0.17 & 0.07 & 0.79 & 0.1604 & 0.69 \\
\hline $\mathrm{FP} * \mathrm{FG}$ & 1 & 19.83 & $<0.0001$ & 24.93 & $<0.0001$ & 0.07 & 0.79 & 2.99 & 0.08 & 0.7424 & 0.39 \\
\hline
\end{tabular}




\begin{tabular}{|l|c|cc|cc|cc|c|c|c|c|} 
Genotype (G) & 4 & 34.90 & $<0.0001$ & 33.96 & $<0.0001$ & 2.42 & 0.66 & 2.19 & 0.70 & 7.5830 & 0.11 \\
FPx G & 4 & 21.80 & $<0.0001$ & 33.76 & $<0.0001$ & 3.56 & 0.47 & 11.76 & 0.02 & 2.2611 & 0.69 \\
FGx G & 4 & 6.60 & 0.16 & 1.84 & 0.28 & 7.24 & 0.12 & 6.85 & 0.14 & 6.8474 & 0.14 \\
FPx FGx G & 4 & 4.98 & 0.2897 & 8.62 & 0.07 & 8.71 & 0.07 & 7.59 & 0.11 & 4.1841 & 0.38 \\
\hline
\end{tabular}


Table 3. Analysis of variance for different grain quality parameters (d.f.: degrees of freedom; Chisq: Type II Wald Chi-square tests).

\begin{tabular}{|c|c|c|c|c|c|c|c|c|c|}
\hline \multirow{3}{*}{ Source } & \multicolumn{9}{|c|}{2014} \\
\hline & \multirow[t]{2}{*}{ d.f } & \multicolumn{2}{|c|}{ D-hordeins } & \multicolumn{2}{|c|}{ C-hordeins } & \multicolumn{2}{|c|}{ B-hordeins } & \multicolumn{2}{|c|}{$\begin{array}{c}\text { Total hordeins } \\
\text { content }\end{array}$} \\
\hline & & Chisq & p-value & Chisq & p-value & Chisq & p-value & Chisq & p-value \\
\hline F.poae (FP) & 1 & 23.27 & $<0.0001$ & 29.55 & $<0.0001$ & 15.11 & $<0.0001$ & 28.09 & $<0.0001$ \\
\hline F. graminearum (FG) & 1 & 25.92 & $<0.0001$ & 34.31 & $<0.0001$ & 12.40 & 0.0004 & 29.73 & $<0.0001$ \\
\hline $\mathrm{FP}^{*} \mathrm{FG}$ & 1 & 25.83 & $<0.0001$ & 37.90 & $<0.0001$ & 5.01 & 0.03 & 26.60 & $<0.0001$ \\
\hline Genotype (G) & 4 & 13.09 & 0.01 & 2.44 & 0.66 & 10.13 & 0.04 & 6.02 & 0.20 \\
\hline $\mathrm{FP} \times \mathrm{G}$ & 4 & 7.01 & 0.14 & 0.93 & 0.92 & 8.24 & 0.08 & 3.48 & 0.48 \\
\hline FG x G & 4 & 8.82 & 0.07 & 0.65 & 0.96 & 2.57 & 0.63 & 1.39 & 0.85 \\
\hline $\mathrm{FP} \times \mathrm{FG} \times \mathrm{G}$ & 4 & 0.99 & 0.43 & 2.39 & 0.67 & 5.28 & 0.26 & 2.14 & 0.71 \\
\hline Fusarium Treatments & \multicolumn{3}{|c|}{ Mean \pm SEM } & \multicolumn{2}{|c|}{ Mean \pm SEM } & \multicolumn{2}{|c|}{ Mean \pm SEM } & \multicolumn{2}{|c|}{ Mean \pm SEM } \\
\hline $\mathrm{FP}_{1} \mathrm{FG}_{0}$ & & \multicolumn{2}{|c|}{$6.24 \pm 1.06 \mathrm{a}$} & \multicolumn{2}{|c|}{$32.03 \pm 4.75 \mathrm{a}$} & \multicolumn{2}{|c|}{$57.69 \pm 9.10 \mathrm{a}$} & \multicolumn{2}{|c|}{$95.96 \pm 12.40 \mathrm{a}$} \\
\hline $\mathrm{FP}_{0} \mathrm{FG}_{1}$ & & \multirow{2}{*}{\multicolumn{2}{|c|}{$\begin{array}{l}5.51 \pm 1.05 \mathrm{a} \\
6.22 \pm 0.95 \mathrm{a}\end{array}$}} & \multirow{2}{*}{\multicolumn{2}{|c|}{$\begin{array}{l}27.52 \pm 5.89 a \\
35.23 \pm 9.15 a\end{array}$}} & \multirow{2}{*}{\multicolumn{2}{|c|}{$\begin{array}{l}60.14 \pm 9.35 a \\
49.10 \pm 5.60 a\end{array}$}} & \multirow{2}{*}{\multicolumn{2}{|c|}{$\begin{array}{l}93.17 \pm 15.15 a \\
90.54 \pm 14.26 a\end{array}$}} \\
\hline $\mathrm{FP}_{1} \mathrm{FG}_{1}$ & & & & & & & & & \\
\hline $\mathrm{FP}_{0} \mathrm{FG}_{0}$ & & \multicolumn{2}{|c|}{$33.21 \pm 5.07 b$} & \multicolumn{2}{|c|}{$155.94 \pm 7.91 \quad b$} & \multicolumn{2}{|c|}{$98.70 \pm 9.31 \quad b$} & \multicolumn{2}{|c|}{$287.85 \pm 17.89 b$} \\
\hline
\end{tabular}

This article is protected by copyright. All rights reserved. 
Table 4. Grain contamination with deoxynivalenol (DON), 3-acetyl deoxynivalenol (3-ADON), 15-acetyl deoxynivalenol (15-ADON) and nivalenol (NIV) in five barley genotypes during 2014, 2015 and 2016 growing seasons. Mean \pm SEM values were from the log transformed data.

\begin{tabular}{|c|c|c|c|c|c|}
\hline Year & Inoculation & $\begin{array}{l}\text { DON } \\
(\mu g / g) \\
\end{array}$ & $\begin{array}{c}\text { 3-ADON } \\
(\mu \mathrm{g} / \mathrm{g}) \\
\end{array}$ & $\begin{array}{c}\text { 15-ADON } \\
(\mu \mathrm{g} / \mathrm{g}) \\
\end{array}$ & $\begin{array}{l}\text { NIV } \\
(\mu g / g) \\
\end{array}$ \\
\hline 2014 & $\begin{array}{l}\text { F. poae } \\
\text { F. graminearum } \\
\text { F. poae / F. graminearum } \\
\text { Control }\end{array}$ & $\begin{array}{c}\text { n.d. } \\
6.12 \pm 1.77 \\
4.69 \pm 1.35 \\
1.87 \pm 0.54\end{array}$ & $\begin{array}{c}\text { n.d. } \\
14.60 \pm 7.71 \\
21.60 \pm 11.41 \\
4.20 \pm 2.22\end{array}$ & $\begin{array}{l}\text { n.d. } \\
1.21 \pm 0.05 \\
1.18 \pm 0.05 \\
\text { n.d. }\end{array}$ & $\begin{array}{l}1.18 \pm 0.06 \\
\text { n.d. } \\
1.20 \pm 0.06 \\
\text { n.d. }\end{array}$ \\
\hline 2015 & $\begin{array}{l}\text { F. poae } \\
\text { F. graminearum } \\
\text { F. poae / F. graminearum } \\
\text { Control }\end{array}$ & $\begin{array}{c}\text { n.d. } \\
1.53 \pm 0.11 \\
1.37 \pm 0.09 \\
1.46 \pm 0.10\end{array}$ & $\begin{array}{c}\text { n.d. } \\
3.97 \pm 0.98 \\
5.20 \pm 1.29 \\
3.74 \pm 0.93\end{array}$ & $\begin{array}{l}1.29 \pm 0.10 \\
1.39 \pm 0.11 \\
1.41 \pm 0.11 \\
1.26 \pm 0.10\end{array}$ & $\begin{array}{l}\text { n.d. } \\
\text { n.d. } \\
\text { n.d. } \\
\text { n.d. }\end{array}$ \\
\hline 2016 & $\begin{array}{l}\text { F. poae } \\
\text { F. graminearum } \\
\text { F. poae / F. graminearum } \\
\text { Control }\end{array}$ & $\begin{array}{c}\text { n.d. } \\
1.02 \pm 0.002 \\
1.02 \pm 0.002 \\
\text { n.d. }\end{array}$ & $\begin{array}{c}\text { n.d. } \\
2.58 \pm 0.30 \\
2.38 \pm 0.28 \\
2.83 \pm 0.34\end{array}$ & $\begin{array}{c}\text { n.d. } \\
1.39 \pm 0.11 \\
1.41 \pm 0.11 \\
\text { n.d. }\end{array}$ & $\begin{array}{l}\text { n.d. } \\
\text { n.d. } \\
\text { n.d. } \\
\text { n.d. }\end{array}$ \\
\hline
\end{tabular}

*nd: non detected 


\section{Figure legends}

Fig.1. Left: Incidence (A), severity (B) and FHB Index (C) values for different treatments in 2014, 2015 and 2016. Right: Differences between genotypes for incidence (D), severity (E) and FHB Index (F) in 2015 growing seasons. Treatments: F. poae ( $\left.\mathrm{FP}_{1} \mathrm{FG}_{0}\right), F$. graminearum $\left(\mathrm{FP}_{0} \mathrm{FG}_{1}\right)$, both pathogens $\left(\mathrm{FP}_{1} \mathrm{FG}_{1}\right)$ and control without Fusarium $\left(\mathrm{FP}_{0} \mathrm{FG}_{0}\right)$. Mean \pm SEM. Columns with different letters are statistically different according to Tukey's test at $\mathrm{p} \leq 0.05$.

Fig.2. Relative abundance and fractions of polyacrylamide gel (SDS-PAGE; T\% = 13.5\%) showing the pattern of D-hordeins, C-hordeins, and B-hordeins. Treatments: F. poae $\left(\mathrm{FP}_{1} \mathrm{FG}_{0}\right), F$. graminearum $\left(\mathrm{FP}_{0} \mathrm{FG}_{1}\right)$, both pathogens $\left(\mathrm{FP}_{1} \mathrm{FG}_{1}\right)$ and control without Fusarium $\left(\mathrm{FP}_{0} \mathrm{FG}_{0}\right)$. 

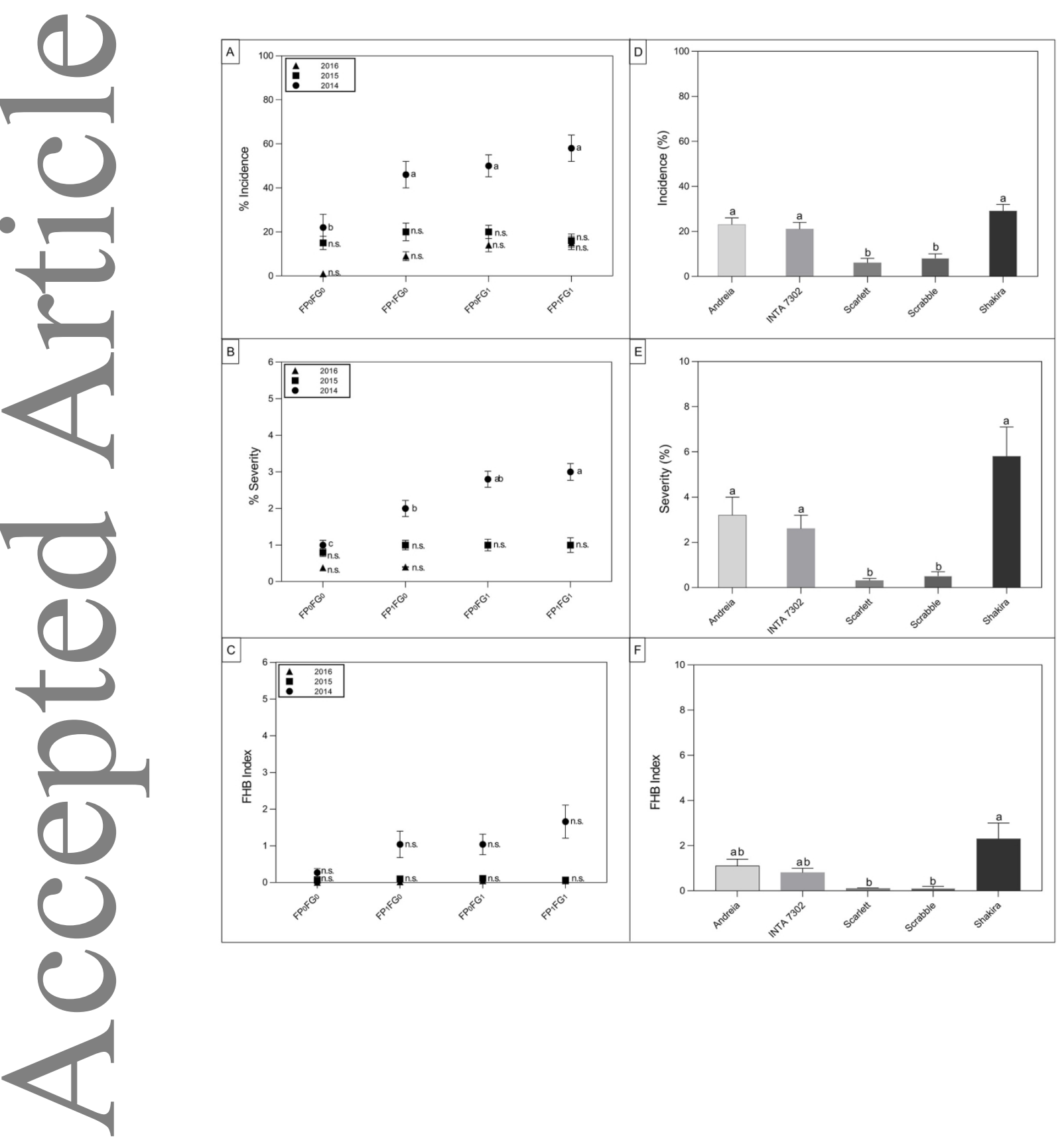

This article is protected by copyright. All rights reserved. 


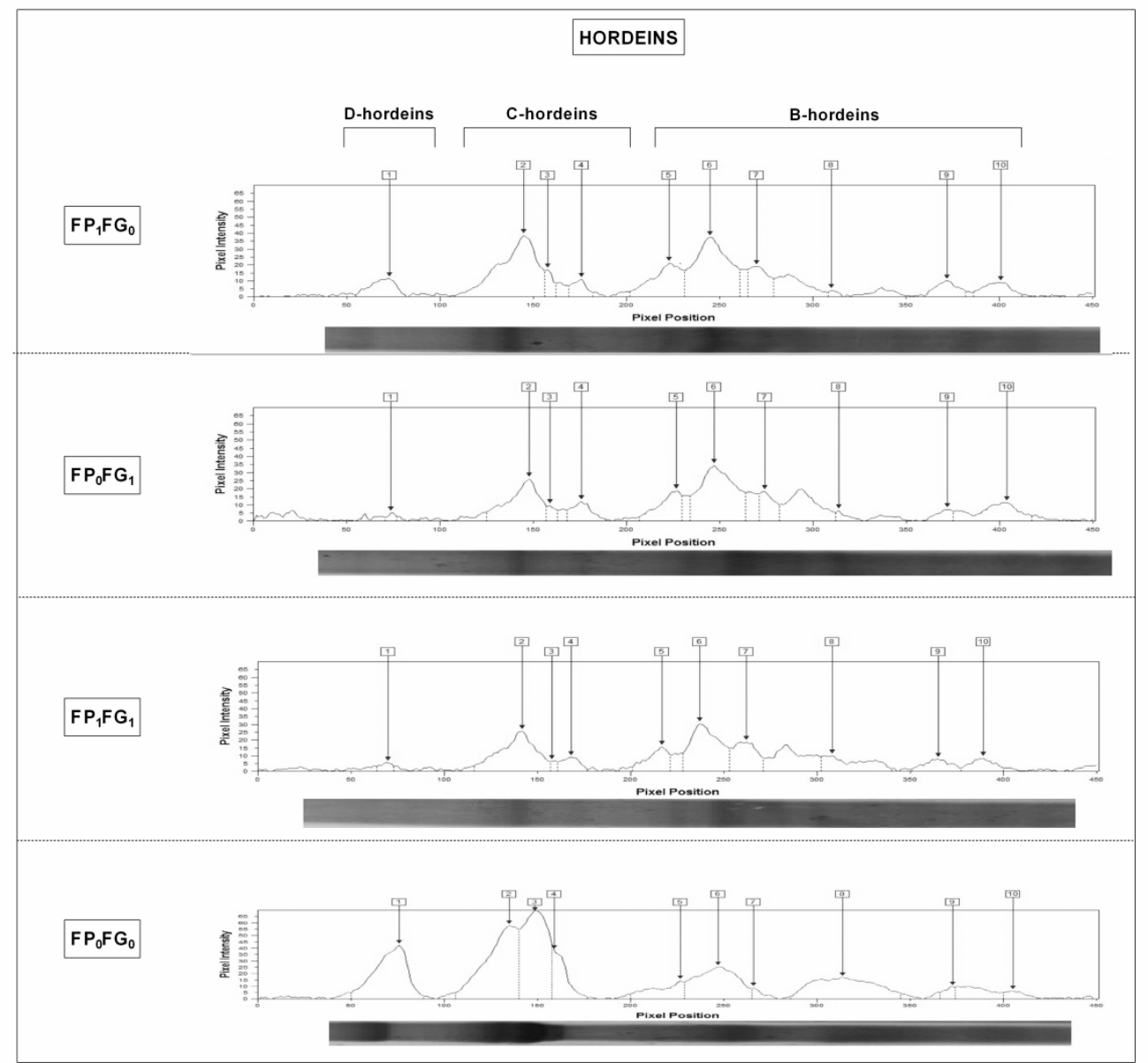

This article is protected by copyright. All rights reserved. 